\title{
Polish Pregnancy-related Assessment Monitoring System (Pol-PrAMS): research on lifestyle health behaviours of Polish women during gestation - study design
}

\author{
Cezary Wojtyła', Paulina Wojtyła-Buciora ${ }^{2,3}$ \\ ${ }^{1}$ Centre of Postgraduate Medical Education, First Department of Obstetrics and Gynaecology, Warsaw, Poland \\ 2Department of Physiology, University of Medical Sciences, Poznan, Poland \\ ${ }^{3}$ Higher Vocational State School, Kalisz, Poland
}

ADDRESS FOR CORRESPONDENCE: Cezary Wojtyła, First Department of Obstetrics and Gynaecology, Centre of Postgraduate Medical Education in Warsaw, 231 Czerniakowska Street, 00-416 Warsaw, Poland, e-mail: czwo@op.pl

\section{INTRODUCTION}

There has been a marked decline in infant mortality during the first year of life observed within the last century in Poland. After regaining independence in 1918, Poland was a country where epidemiological transformations were substantially delayed as was reflected, amongst other things, by the infant mortality rate. In the inter-war period, this rate was estimated at 150/1000 live births, with $40 \%$ of children not surviving beyond the age of five years $[1,2]$. This contrasts with an infant mortality rate of $15 \%$ in Sweden in 1920 [1]. The Second World War and the resulting health collapse were hardly conducive to the Polish health situation. After the war a centralised healthcare system in the Eastern bloc countries was introduced (the so-called Siemaszko model), leading to health improvements in Poland. An important feature of this system was to create an effective programme of mother and child healthcare [1]. A new staff intake of paediatricians, nurses, and midwives were educated. Such changes brought about impressive declines of infant mortality [1, 3]. Whilst in 1950 the infant mortality rate was $109 / 1000$ live births, already in 1960 this had fallen by a half to $55 / 1000$ live births [1]. Subsequent years showed further improvements for infant mortality, but it was not until the $21^{\text {st }}$ century observed, rates are comparable to other European countries. In 2014, Poland achieved an infant mortality rate of 4.22/1000 live births, while those in Germany, Spain, and Sweden were, respectively, 3.19, 2.89, and 2.18/1000 live births (Fig. 1) [1, 4, 5]. In fact, since the year 2000 the rate has fallen by over 50\% [6].
More than half of all infant deaths usually happen in the first week of life, and another 30\% after the age of four weeks [7]. In Poland, the main causes of infant deaths are diseases during the perinatal period. Over the last decade the mortality rate due to such reasons has constantly risen. In 2001 this was responsible for $49.9 \%$ of child deaths in the first year of life, whilst in 2010 it reached $51.5 \%$. This rise was mainly due to a significant increase in infant mortality due to premature birth and low birth weight. In 2001 the percentage of infant deaths because of prematurity and low birth weight reached $19.8 \%$ and in 2010 it was $33.1 \%$. Infant deaths due to congenital anomalies have persisted at a comparable level of $34 \%$ [7].

The neonatal mortality rate, especially the early one (of up to seven days old), indicates the state of pregnant women's healthcare in any given country $[8,9]$. In Poland, this rate for 2010 was 2.6/1000 live births, whilst in 2014 it was 2.08/1000 live births, and it is still one of the highest in Europe. Nevertheless, it should be stressed that such differences between Poland and the rest of the EU are currently small and remain at a satisfactory level $[6,9]$. Figure 2 shows early and late neonatal mortality in selected European countries [10].

The main cause of neonatal mortality in high-income countries is the immaturity of children resulting from prematurity and birth defects [9]. As mentioned previously, there has been a significant increase in child mortality in Poland due to premature birth and low birth weight. Such complications are often linked to 


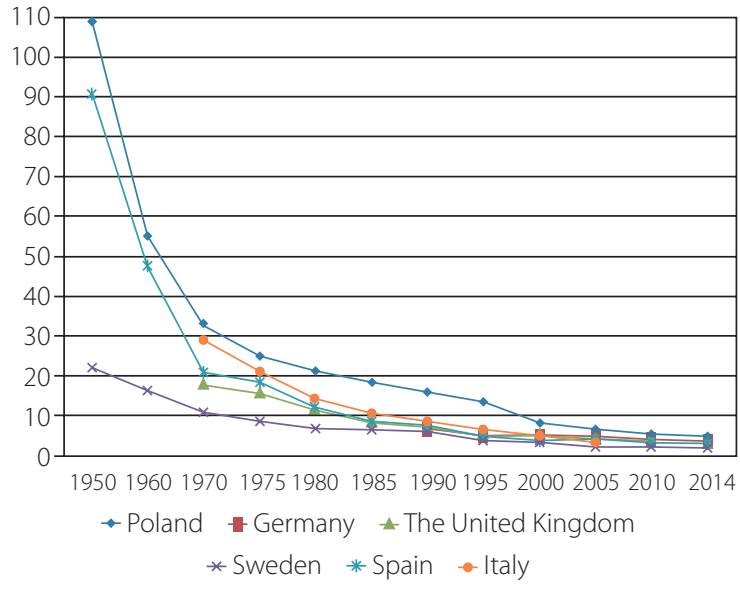

FIG. 1. Infant deaths per 1000 live births

the development of chronic disease like hypertension or metabolic diseases. It is known that women's lifestyle affects to the development of these diseases [9]. Smoking, alcohol, and psychoactive substance abuse together with, obesity, poor diet, and low physical activity predispose an individual to develop these diseases and consequently, increase neonatal mortality. These are factors that can also be modified according to an appropriate health policy. In order to apply concrete solutions, it is necessary to know the scale of these problems and to define the lifestyle of pregnant women, as well as their motivations for avoiding particular behaviours that may lead to complications for their pregnancy, such as: low birth weight, premature birth, poor condition of the newborn after birth, and the development of ges- tational diabetes mellitus or hypertension during pregnancy. So that the correct conclusions can be drawn, a suitable study needs to be undertaken on a large and representative cohort of women. To this end, the Polish Pregnancy-related Assessment Monitoring System (Pol-PrAMS) has been designed in order to monitor maternal and child health. It is based on a model that has been running in the USA since 1987, also similarly entitled the 'Pregnancy Risk Assessment Monitoring System’ (PRAMS).

\section{MATERIAL AND METHODS}

For the purposes of monitoring maternal and child health, a survey was undertaken on those women who after giving birth stayed in hospitals that had in their structure at least one of the following units: maternity ward, department of gynaecology - obstetrics, department of obstetrics with rooming-in, labour ward, or neonatal department. The study was conducted simultaneously throughout the whole country. Its aim was to assess the health behaviour of pregnant women in Poland by considering the following aspects: physical activity, diet and its supplementation, smoking, alcohol consumption, and psychoactive substance abuse, as well as evaluation of pregnancy, childbirth, and the status of the newborn and mother after birth.

Analyses of the population of pregnant women in Poland were made using a questionnaire survey based on the Pol-PrAMS programme (Polish Pregnancy-related Assessment Monitoring System). The questionnaire was modelled on the questionnaire used in the United States
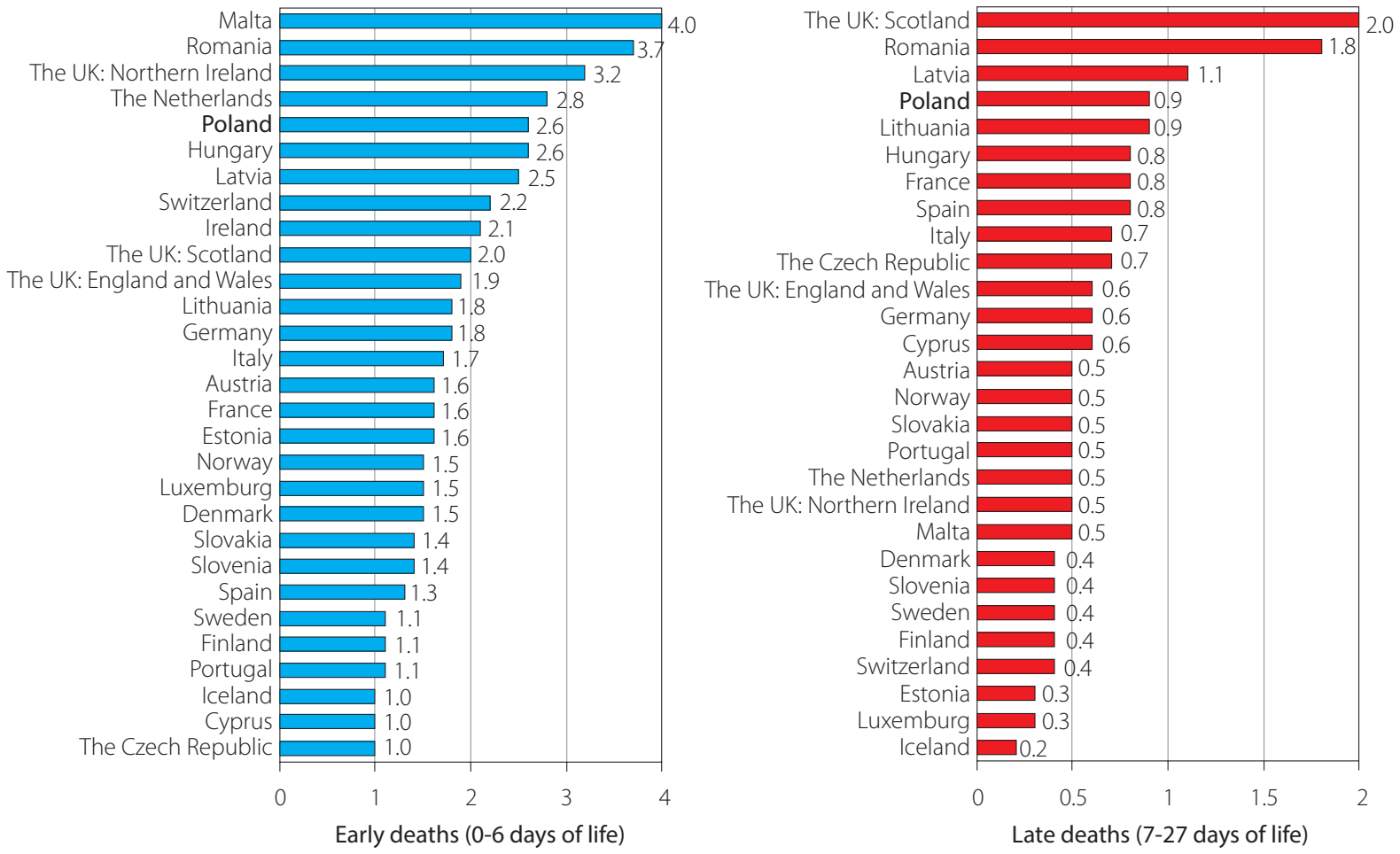

FIG. 2. Early and late neonatal mortality rates per 1000 live births in 2010 , in selected European countries 
within the PRAMS project (Pregnancy Risk Assessment Monitoring Survey) [11]. The PRAMS project has been conducted annually in the US since 1987. Survey questions correspond to randomly selected women in the first 7 days after birth by e-mail, or if there is no answer, by telephone. Thus, annually about 1300-3300 women take part in the project, in each state [12].

For every year preceding the study, the Chief Sanitary Inspector had defined a given week assigned for carrying out the studies throughout the country, as laid out in its published Communication. This week occurred on different months so as to obtain a representative study group. It was, however, suspected that seasonality may affect the number of births. Each Regional Sanitary-Epidemiological Station therefore fixed a precise date for carrying out the study as defined in the Chief Sanitary Inspector's Communication, reporting this fact to the National Coordinator of research in the Chief Sanitary Inspectorate. The National Coordinator of research then marked the deadline for entering data online, to the prepared answer sheet. The geographical area of Poland was divided into four zones for which the interviewers were obliged to enter their data at different times. This was designed to prevent any difficulties arising with the technical capabilities of the applied system upon entering survey data.

In a ruling issued by the Chief Sanitary Inspector, the methodological basics for conducting studies was provided, which had previously received approval of the Bioethics Committee functionally operating at the Institute of Rural Health in Lublin. The study was performed by trained interviewers working at the Regional Sanitary-Epidemiological Stations, who had been previously trained by experts from the Department of Health Promotion at the Chief Sanitary Inspectorate as well as from the Provincial Sanitary - Epidemiological, using a cascade system.

Permission to carry out the survey had also been received from the Director of each hospital. The study was preceded by sending a letter of endorsement to the obstetricians, signed by the National Consultant for Obstetrics and Gynaecology. The study was conducted on a randomised group of Polish women and their children and was conducted in all Polish hospitals.

\section{OUESTIONNAIRE DESIGN FOR THE STUDY}

The study was conducted using a questionnaire survey, which was prepared by the Chief Sanitary Inspector in conjunction with Polish experts specialising in this field. It was divided into three parts. The first part contains 77 questions about: maternal age, place of residence, education, marital status, family social and economic status, maternity profile (i.e. earlier births, miscarriage, possible difficulties in conceiving), and risky health behaviours before and during pregnancy (e.g. smoking, alcohol, drugs and other psychoactive substance abuse). Mothers who remained in hospital with their newborns after birth completed the first part of the survey. The second part had nine questions that were filled-in by the medical personnel (doctor, nurse, midwife) providing healthcare to the mother and newborn, with the use of medical records (pregnancy cards and patient's medical history). The questions in this part concerned the childbirth method, newborn status after birth, and birth defects. It also included questions about the results of laboratory tests performed on mothers and newborns after birth. The final part of the questionnaire was addressed to the interviewer and included information such as: dates, survey number, place of residence, and district and hospital department in which the woman stayed after giving birth.

\section{PILOT STUDIES}

The first study of this kind was carried out in Poland in 2009. It was a pilot study. The survey took place on one defined day in the second week of July 2009. A questionnaire was used in a face-to-face method, i.e. a direct interview conducted with the patient by a properly trained interviewer. Out of all 402 hospitals where births took place in Poland, 382 (95\%) agreed to participate, with 3346 women $(81.6 \%)$ replying to the questionnaire, out of which 3280 (98\%) questionnaires were qualified for statistical analysis. On that day, the total number of women giving birth in all hospitals in Poland was 4100 .

\section{MAIN STUDIES}

In 2010, research was conducted in the second week of August. The method of data collection was modified with the introduction of individual completion of the survey by both the mothers and the medical staff.

The first part of the survey was extended to cover questions on weight and nutrition before and during pregnancy, amongst others. This included mealtime rates, meal quality, nutritional supplementation, taking vitamins and medication, and physical activity. Also included were questions regarding hypertension and diabetes before and during pregnancy, as well as those concerning whether women had undergone preventive monitoring for breast and cervical cancer, together with information about screening for group B streptococcus during pregnancy. Women's knowledge on taking cancer prevention measures was also assessed. The second part of the survey, intended for medical staff, was also expanded to provide information on blood tests performed during pregnancy and postpartum in women and newborns, together with any birth defect data. Out of all the 398 hospitals where children were born in Poland, the Directors of 373 (94\%) gave their permission for the study. On the actual day of the study, the total number of women giving birth was 3979 of whom 3064 (77\%) were included in the study in the hospitals that agreed to take part. Of these, 2893 (94.4\%) women qualified for statistical analysis, who had replied to at least one question from the survey questionnaire. 


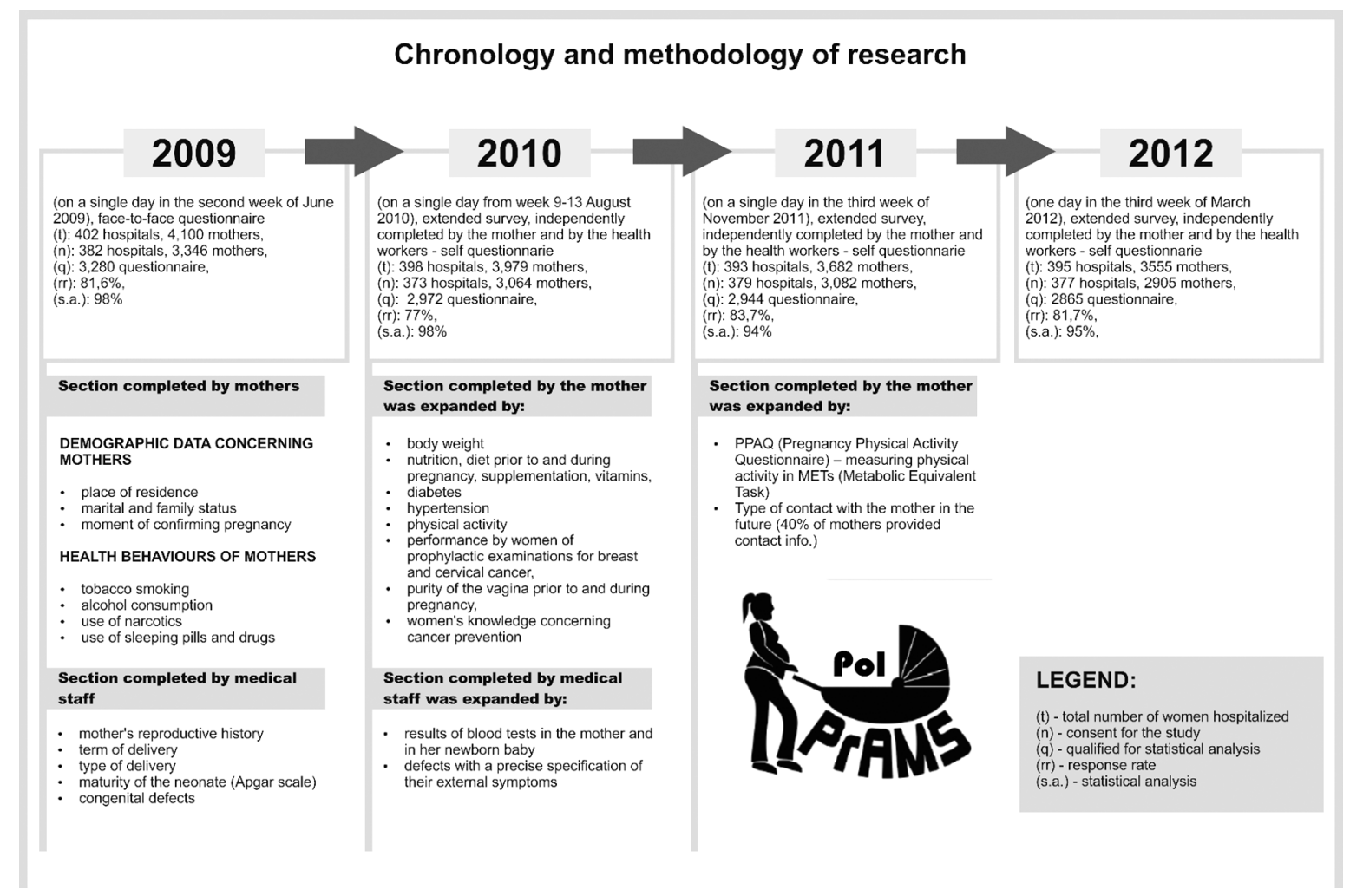

FIG. 3. Chronology and methodology of research

In 2011, the Pol-PrAMS study was performed on the third week of November, according to the above methodology. There were 3682 births for that time in Poland at 393 hospitals. Permission for the study was granted by 379 hospitals, which included 3082 mothers (83.7\%) and their newborns. For statistical analyses we qualified 2899 surveys $(94.1 \%)$. The survey questions were extended to those performing physical activity in the third trimester of pregnancy by using the Pregnancy Physical Activity Questionnaire (PPAQ) [13]. This comprised 32 survey questions concerning physical activity undertaken daily by pregnant women, such as: domestic work (household activity) or childcare (caregiving activity), work-related (occupational activity), physical activity during leisure time or at school (sports/exercise), and sedentary time (inactivity) [14]. Instructions for completing these questions were provided in each survey question. The third trimester of pregnancy was so chosen because subjects

TABLE 1. Number of women qualified for the study during 2010-2012

Study year Number of women qualified for the study

\begin{tabular}{|l|c|}
\hline 2010 & 2893 \\
\hline 2011 & 2899 \\
\hline 2012 & 2833 \\
\hline Total & 8625 \\
\hline
\end{tabular}

filled in the questionnaires just after childbirth. The daily time spent on each of the activities surveyed was then multiplied by its intensity, in order to estimate the average weekly energy expenditure as measured by the Metabolic Equivalents of Task (MET) per hour per week, i.e. METh-week, attributable to each type of activity performed by pregnant women during the day. According to the PPAQ instructions, the weekly time spent on the various activities were then multiplied by their intensities. Actual values of intensity for each physical activity were taken from the widely used Compendium-based MET values [15].

For 2012, the study was undertaken on one day in the third week of March, according to the methodology used in the years 2010 and 2011. Survey questions in 2012 were the same as in the previous year. There were 3555 childbirths in 395 hospitals in Poland on these days, where 377 hospitals gave their permission for doing the study. This accounted for 2905 women subjects (81.7\%), of whom 2833 qualified for statistical analyses (97.5\%). The chronology and methodology of research and the scope of the information obtained are shown in Figure 3.

The data so obtained were then entered into answer sheets by the interviewers for subsequent statistical analyses, which were then published as annual reports.

As mentioned previously, studies were conducted on different months of each year so as to forestall any effect of seasonal variation in the Polish birth rates. There were, however, no differences in birth rates for the months of the year that the survey was carried out in, nor in the 
TABLE 2. Characteristic of the surveyed women

\begin{tabular}{|c|c|}
\hline \multicolumn{2}{|l|}{ Age } \\
\hline$<20$ yrs & $4.1 \%$ \\
\hline $20-25$ yrs & $24.8 \%$ \\
\hline $26-30$ yrs & $40.0 \%$ \\
\hline $31-35$ yrs & $22.3 \%$ \\
\hline$>35$ yrs & $8.8 \%$ \\
\hline \multicolumn{2}{|c|}{ Place of residence } \\
\hline City $>500 \mathrm{~K}$ & $11.2 \%$ \\
\hline $100-500 \mathrm{~K}$ & $13.4 \%$ \\
\hline $50-100 \mathrm{~K}$ & $11.1 \%$ \\
\hline$<50 \mathrm{~K}$ & $21.8 \%$ \\
\hline Rural & $42.4 \%$ \\
\hline \multicolumn{2}{|c|}{ Economic means assessment } \\
\hline Very good & $9.5 \%$ \\
\hline Good & $56.5 \%$ \\
\hline Average & $32.6 \%$ \\
\hline Bad & $1.4 \%$ \\
\hline \multicolumn{2}{|c|}{ Assessment of social-living conditions } \\
\hline Very good & $24.1 \%$ \\
\hline Good & $56.4 \%$ \\
\hline Average & $19 \%$ \\
\hline Bad & $0.5 \%$ \\
\hline
\end{tabular}

numbers of women having their first, second, or subsequent babies.

\section{CHARACTERISTICS OF THE STUDY GROUP}

In order to determine how representative the women's sample is for the rest of Poland, selected variables that defined the study group were compared with available data on the general population by means of the Polish Statistical Yearbook, CSO 2011 [16], using the Pearson's $\chi^{2}$ test. The compared variables were: women's age distribution, place of residence (i.e. urban vs. rural and provincial region), and newborn gender; with no significant differences being found. The Pearson's correlation was used to assess marital status of the mother and their education level with the general population, where the coefficients so calculated were close to unity (from 0.98 to $0.99, p<0.05$ ). Differences in the duration of pregnancy were, however, observed between the study group and the population nationwide.

The survey was conducted in all hospitals in Poland, where women gave birth. The analysis did not include pilot studies, i.e. any women giving birth in 2009. The grand total of female subjects studied between 2010 and 2012 was 9051 women with their newborns. Those replying to the questionnaire amounted to 8625 women
TABLE 3. Summary of questionnaire data collected in Pol-PrAMS study, part I

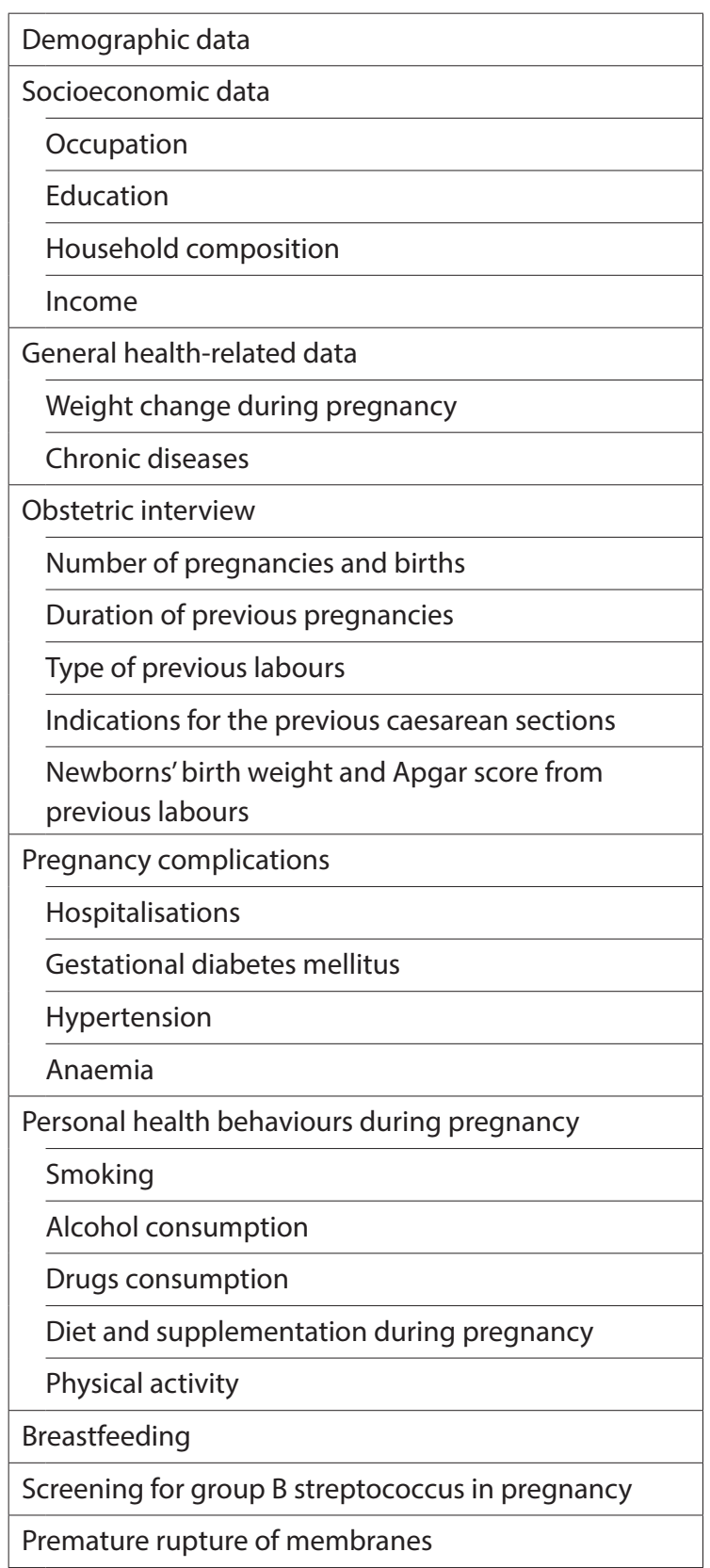

(95.3\%). These were women who answered at least one question from the questionnaire. This represents $76.9 \%$ of all women in Polish maternity wards on the particular study days. Table 1 shows the number of women enrolled for 2010-2012, whilst Table 2 shows their characteristics.

\section{INFORMATION OBTAINED}

Because the surveys were carried out on such a large and representative sample of pregnant women, it allowed the following areas to be investigated:

- active and passive smoking rates for women before and during pregnancy, as well as alcohol consumption, dietary changes, dietary supplementation, types 
TABLE 4. Summary of questionnaire data collected in the Pol-PrAMS study, part II

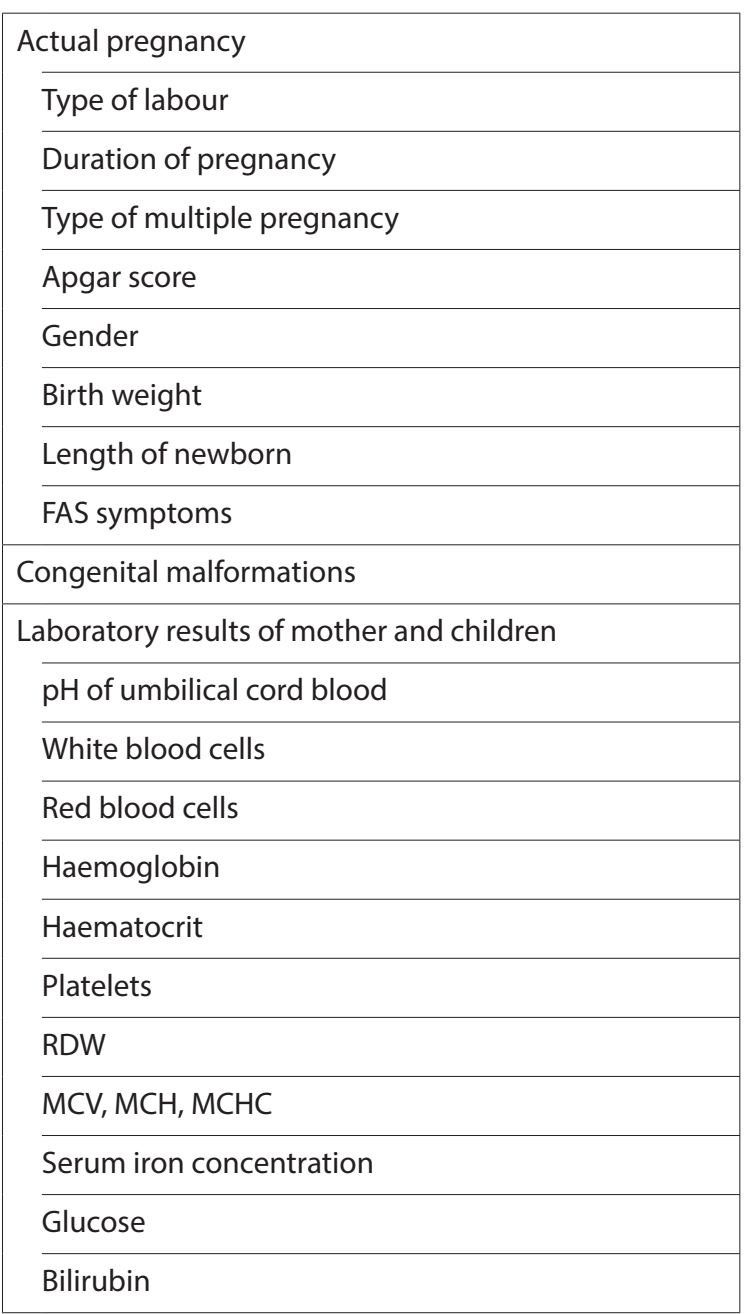

of physical activity, and psychoactive substance abuse during pregnancy,

- prevalence of diseases associated with pregnancy like hypertension, diabetes mellitus, or anaemia,

- evaluating women's awareness of the effect of their lifestyle behaviours during pregnancy on their health and that of their offspring,

- prevalence of selected chronic diseases in pregnant women,

- determining the proportion of women who breastfed,

- evaluating the course of labour,

- newborn assessment after delivery and prevalence of birth defects,

- evaluating laboratory test results for women and newborns after birth,

- analysing the impact of pregnancy on obstetric outcome.

When completing the questionnaires, women were also asked questions on cervical and breast cancer screening, which allowed us to establish their knowledge on the causes of these disorders as well as determining the screening methods undertaken. The survey was volun- tary and was performed anonymously to minimise any data falsification. The mothers' data obtained from the first part of the survey are presented in Table 3, whilst data from medical staff are shown in Table 4 . The survey form is included to this paper as a WebAppendix.

\section{SUMMARY}

The Pol-PrAMS studies are the only ones carried out so far in Poland, for such a large and representative sample of pregnant women. The scope of the data allows the health behaviour of pregnant women to be evaluated together with their habits, levels of knowledge, and motivation for making lifestyle changes arising from their pregnancy. It will also help to assess the effect of different factors on obstetric outcome, which can thus permit any negative consequences to be counteracted in the future through introducing appropriate healthcare system solutions for pregnant women.

\section{DISCLOSURE}

Authors report no conflict of interest.

\section{References}

1. Zatoński A, Zatoński M. Sytuacja zdrowotna w Polsce Ludowej [Health situation in People's Poland]. In: Noszczyk W (ed.). Zarys dziejów medycyny w Polsce. Tom 3. 1944-1989 [History of medicine in Poland. Volume3. 1944-1989]. PZWL, Warszawa 2016.

2. Mały Rocznik Statystyczny 1939 [Little Statistical Yearbook 1939]. Główny Urząd Statystyczny Rzeczypospolitej Polskiej, Warszawa 1939 , p. 51

3. Maciejewski T. Rozwój opieki perinatalnej na przełomie XX i XXI wieku [The development of perinatal care between XX and XXI century]. Perinatol Neonatol Ginekol 2013; 6: 136-140.

4. World Health Organization. European health for all database. Early and late neonatal deaths. Available from: http://www.euro. who.int/en/data-and-evidence/databases/european-healthfor-all-database-hfa-db (accesed: 16 February 2016).

5. The UN Inter-agency Group for Child Mortality Estimation. Estimates for under-five, infant and neonatal mortality. Available from: http://www.childmortality.org/ (accessed: 11 January 2016).

6. World Health Organization. European health for all database. Early and late neonatal deaths. Available from: http://www.euro. who.int/en/data-and-evidence/databases/european-healthfor-all-database-hfa-db (accesed: 16 February 2016).

7. Wojtyniak B, Goryński P, Moskalewicz B. Sytuacja zdrowotna ludności Polski i jej uwarunkowania [Health situation of the Polish population and its determinants]. Narodowy Instytut Zdrowia Publicznego - Państwowy Zakład Higieny, Warszawa 2012.

8. World Health Organization. Neonatal and perinatal mortality: country, regional and global estimates. WHO, Geneva 2006.

9. Zeitlin J, Mohangoo A, Delnord M. European perinatal health report: Health and Care of Pregnant Women and Babies in Europe in 2010.

10. Euro-Peristat project with SCPE and Eurocat. European Perinatal Health Report. The health and care of pregnant women and babies in Europe in 2010. May 2013. 
11. Center for Disease Control and Prevention. PRAMS. Available from: http://www.cdc.gov/prams/ (accessed: 16 February 2016).

12. Shulman HB, Gilbert BC, Msphbrenda CG, et al. The Pregnancy Risk Assessment Monitoring System (PRAMS): current methods and evaluation of 2001 response rates. Public Health Rep 2006; 121: 74-83.

13. Chasan-Taber L, Schmidt MD, Roberts DE, et al. Development and validation of a Pregnancy Physical Activity Questionnaire. Med Sci Sports Exerc 2004; 36: 1750-1760. Erratum in: Med Sci Sports Exerc 2011; 43: 195.

14. Pregnancy Physical Activity Questionnaire - Instruction. Available from:http://dapa-toolkit.mrc.ac.uk/documents/en/PPA/PPAQ_ instructions_1.pdf (accessed: 17 January 2016).

15. Ainsworth BE, Haskell WL, Whitt MC, et al. Compendium of physical activities: an update of activity codes and MET intensities. Med Sci Sports Exerc 2000; 32: S498-S516.

16. Central Statistical Office of Poland. Statistical yearbook of the Republic of Poland 2011. Zakład Wydawnictw Statystycznych, Warszawa 2011.

\section{AUTHORS' CONTRIBUTIONS}

CW prepared concept and design of the publication. CW and PWB collected and analysed data. CW wrote the article. CW and PWB participated in its critical revision and final approval. 